\title{
PENGARUH INTENSITAS, TAMPILAN DAN ISI PESAN POSTER KAMPANYE SOSIAL TERHADAP PERILAKU BERKENDARA MAHASISWA
}

\author{
Teddy Dyatmika \\ IAIN Pekalongan \\ teddy.dyatmika@iainpekalongan.ac.id
}

\author{
Dikhorir Afnan \\ Universitas Muhammadiyah Cirebon \\ dik.gassela@gmail.com
}

\begin{abstract}
This research was conducted on students in Muhammadiyah University of Cirebon who were spread in 19 study programs using quantitative methods. The purpose of this research is to know how many effect of message intensity, media appearance and media content to the students behaviour, using social campaigns media in form of posters of raw materials for batik cloth waste. This research found that: (1) the effect of Message Intensity (X1) of safety riding social campaign media to the safety riding behavior of UMC students (Y) was $12.7 \%$, (2)The Effect of Media Appearance (X2) of safety riding social campaign media to the safety riding behavior of UMC students (Y) was 29.2\%, (3) The Effect of Media Content (X3) of safety riding social campaign media to the safety riding behavior of UMC students (Y) was 19.4\%. The effect of Message Intensity (X1), Media Display (X2) and Media Content (X3) of safety riding social campaign media to the safety riding behavior of UMC students (Y) was $52.9 \%$.
\end{abstract}

Keywords: Social campaign, Posters, Batik

\begin{abstract}
Abstrak
Penelitian dilakukan terhadap mahasiswa di lingkungan Universitas Muhammadiyah Cirebon yang tersebar di 19 program studi dengan menggunakan metode kuantitatif. Penelitian ini memiliki tujuan mengetahui seberapa besar pengaruh dari intensitas pesan, tampilan media dan isi media terhadap perilaku mahasiswa Universitas Muhammadiyah Cirebon dengan menggunakan media kampanye sosial berupa poster dari bahan baku limbah kain batik. Hasil penelitian menunjukkan bahwa pengaruh Intensitas Pesan (X1) dari media kampanye sosial safety riding terhadap perilaku mahasiswa UMC dalam berkendara aman (Y) sebesar 12,7\%. PengaruhTampilan Media (X2) dari media kampanyesosialsafety riding terhadapperilakumahasiswa UMC dalamberkendaraaman (Y) sebesar 29,2\%.Pengaruh Isi Media (X3) dari media kampanyesosialsafety riding terhadapperilakumahasiswa UMC dalamberkendaraaman (Y) sebesar 19,4\%. PengaruhIntensitasPesan (X1), Tampilan Media (X2) dan Isi Media (X3) secarabersamasamadari media kampanyesosialsafety riding terhadapperilakumahasiswa UMC dalamberkendaraaman $(Y)$ sebesar 52,9\%.
\end{abstract}

Kata Kunci : Kampanye Sosial, Poster, Batik 


\section{A. PENDAHULUAN}

Tingkat kecelakaan di Republik Indonesia menurut data Korlantas Polri masih cukup tinggi. Pada jangka waktu 3 bulan mulai dari tanggal 1 Januari 2017 hingga 31 Maret 2017 ada 24 ribu jiwa mengalami korban kecelakaan dan sekitar 5 ribu jiwa tercatat meninggal dunia. Dari data tersebut paling tinggi tingkat kecelakaan adalah pengemudi sepeda motor dimana kebanyakan dialami oleh korban dengan usia muda yaitu 1524 tahun. Sepeda motor penyumbang terbesar terjadinya kecelakaan lalu lintas di Indonesia yaitu sebesar $64 \%$ dimana setiap bulannya setidaknya ada 7 ribu kejadian laka lantas yang menimpa pengguna sepeda motor. Kebanyakan korban kecelakan dikarenakan kebut-kebutan dan tidak menggunakan helm saat mengendarai sepeda motr di jalan raya (www.korlantasirsms.info). Catatan ini sungguh sangat mengkhawatirkan. Perlu ada upaya untuk menekan tingkat kecelakan yang ada di Indonesia agar tingkat kecelakan dapat diminimalisir.

Pemerintah dalam hal ini dibantu pihak kepolisian tentu tidak tinggal diam menginformasikan berkendara aman. Segala daya upaya sudah sering dilakukan baik oleh pemerintah melalui dinas perhubungan maupun pihak kepolisian melalui kampanye sosial berkendara aman kepada masyarakat. Berbagai upaya yang sudah dilakukan antara lain program polisi masuk sekolah dan kampus, mengaktifkan patroli keamanan sekolah, mengaktifkan gerakan pramuka saka bhayangkara lantas, kerjasama dengan media cetak dan elektronik dan lain sebagainya. Akan tetapi tetap saja tingkat kecelakaan tinggi terutama pada kalangan anak-anak muda dan kebanyakan menggunakan sepeda motor. Adrenalin yang tinggi yang dimiliki anak muda membuat mereka kurang berhati hati dalam berkendara. Tentu perlu adanya dukungan dari pihak keluarga, sekolah dan juga masyarakat untuk mengedukasi agar para pemuda lebih berhati-hati dalam mengendarai kendaraannya terutama kendaraan sepeda motor di jalan raya. Dari data tersebut peneliti menawarkan media kampanye sosial berkendara aman menggunakan media poster dengan bahan baku yang ramah lingkungan yaitu limbah kain batik. Tingginya limbah kain batik yang ada di kota cirebon coba dimanfaatkan sebagai media kampanye sosial. Dari media ini diharapkan dapat meminimalisir tingkat kecelakaan karena tampilannya yang dibuat semenarik mungkin dengan isi pesan yang mudah dipahami oleh kalangan anak muda. Media kampanye sosial ini di tempatkan di lingkungan kampus Universitas Muhammadiyah Cirebon dengan harapan dapat dilihat secara terus menerus oleh mahasiswa sehingga mahasiswa mengalami perubahan perilaku dalam berkendara secara aman di jalan raya.

Tradisi yang digunakan pada penelitian ini adalah sosiopsikologis dimana pada tradisi ini sifat pribadi seseorang lebih ditonjolkan serta dimana proses kognitif untuk menghasilkan perilaku. Pada tradisi ini juga lebih memperhatikan persuasi dan perubahan sikap dalam memproses pesan, dimana seseorang membuat perencananaan strategi sebuah pesan, seseorang dalam menerima dan memproses pesan dan efeknya pada orang tersebut (Littlejohn, 2009:63).

Teori yang digunakan pada penelitian ini adalah teori pembelajaran sosial 
dimana teori ini masuk dalam salah satu teori persuasif. Teori ini menekankan pada sebuah pengamatan atau observasi tingkah laku dan sikap orang lain. Dimana teori ini mencoba memprediksi tingkah laku orang lain dengan cara mengamati tingkah laku orang lain (Lattimore, 2010:58). Sedangkan menurut Baran dan Davis dalam Hutagalung (2015:43) seseorang dapat melakukan perubahan perilaku mereka setelah orang tersebut melihat perilaku dari orang lain maupun setelah orang tersebut melihat dan menyaksikan pesan dari media massa yang menurut mereka memiliki manfaat bagi dirinya. Menurut teori ini, manusia belajar melalui observasi (dalam hal ini observasi melalui media). Penelitian ini membuat sebuah media kampanye sosial yang berusaha mengubah perilaku orang lain dalam hal ini mahasiswa melalui media poster berbahan baku kain batik bekas agar para mahasiswa dalam berkendara di jalan raya mematuhi peraturan lalu lintas dan berkendara secara aman. Harapannya melalui media kampanye sosial ini tingkat kecelakan di jalan raya yang sebagian besar dari kendaraan bermotor dan akalangan remaja dapat diminimalisir. Oleh karena itu, kampanye sosial melalui media ini dibuat semenarik mungkin dari segi tampilan dan semudah mungkin isi dari pesan dapat dipahami oleh mahasiswa. Hal tersebut sesuai dengan apa yang dikatakan oleh Machfoedz (2010) yaitu sebuah pesan dalam bentuk cetak, untuk menarik perhatian bisa menggunakan inovasi serta perbedaan gambar yang tajam, menarik untuk dipandang, ukuran dan posisi dan pesan teratur dan tepat serta memperhatikan warna, bentuk dan gerakan. Tampilan pesan menjadi penting, meskipun isi pesannya bagus kalau tampilannya kurang menarik maka orang tidak akan membaca pesan yang bagus tersebut. Berbeda jika tampilan media yang disampaikan menarik atau enak dipandang. Orang pasti akan melihat dan mau tidak mau membaca pesan yang ada dalam media tersebut. Hal senada juga disampaikan oleh McLuhan dalam Morrisan (2013:493) media atau saluran komunikasi memiliki kekuatan dan memberikan pengaruhnya kepada masyarakat, dan bukan isi pesannya. Selain dua hal di atas yaitu tampilan media dan isi media, penempatan media kampanye sosial juga ditempatkan pada tempat yang strategis, tujuannya adalah agar tingkat intensitas dari mahasiswa untuk melihat media kampanye sosial tinggi. Ini menjadi sangat penting dikarenakan jika penempatan media tidak ditempat strategis intensitas mahasiswa dalam melihat media kampanye sosial juga akan kecil apalagi intensitas untuk membaca isi dari media tersebut.

\section{B. Metode Penelitian}

Pada penelitian ini menggunakan tipe eksplanatif yaitu dengan cara menghubungkan serta mencari penyebab dan akibat dari beberapa variabel yang diteliti. Pada tipe ini seorag peneliti memerlukan definisi konsep dan kerangka teori untuk mengetahui dugaan awal antar variabelnya (Kriyantono, 2014:69).

Objek penelitian pada penelitian ini adalah mahasiswa Universitas Muhammadiyah Cirebon sebanyak 4.406 mahasiswa yang tersebar di beberapa program studi (www.forlap.dikti. go.id). Peneliti tidak mengambil data dari keseluruhan data yang tersedia, tetapi cukup menggunakan sampel. Dimana teknik pengambilan sampel yang digunakan adalah proporsional sampling. 
Sampel yang diperoleh sebanyak 367 mahasiswa dengan prosentase error sebesar $5 \%$.

Sebelum instrumen di berikan kepada responden, terlebih dahulu kuesioner diujikan terlebih dahulu validitas dan reliabilitasnya. Ada sebanyak 21 pertanyaan yang diujikan kepada 30 responden mahasiswa. Hasilnya seluruh pertanyaan reliebel dan valid dimana realibilitasnya sebesar $92 \%$.

\section{PEMBAHASAN}

Tahapan selanjutnya adalah mengetahui seberapa besar pengaruh yang ditimbulkan dari Intensitas Pesan untuk mengetahui seberapa besar pengaruh yang ditimbulkan dari ketiga variabel independent terhadap satu variabel dependent.

\section{Uji Prasyarat}

1) Uji Normalitas

Pada gambar 2 di bawah ini dapat diketahui mengenai normalitas dari data penelitian ini. Apabila residual berasal dari distribusi normal, maka nilai sebaran akan berada pada sekitar garis lurus. Pada gambar 2 sebaran data hampir semuanya berada pada sumbu normal. Dengan demikian dapat diartikan bahwa pernyataan normalitas dapat terpenuhi.

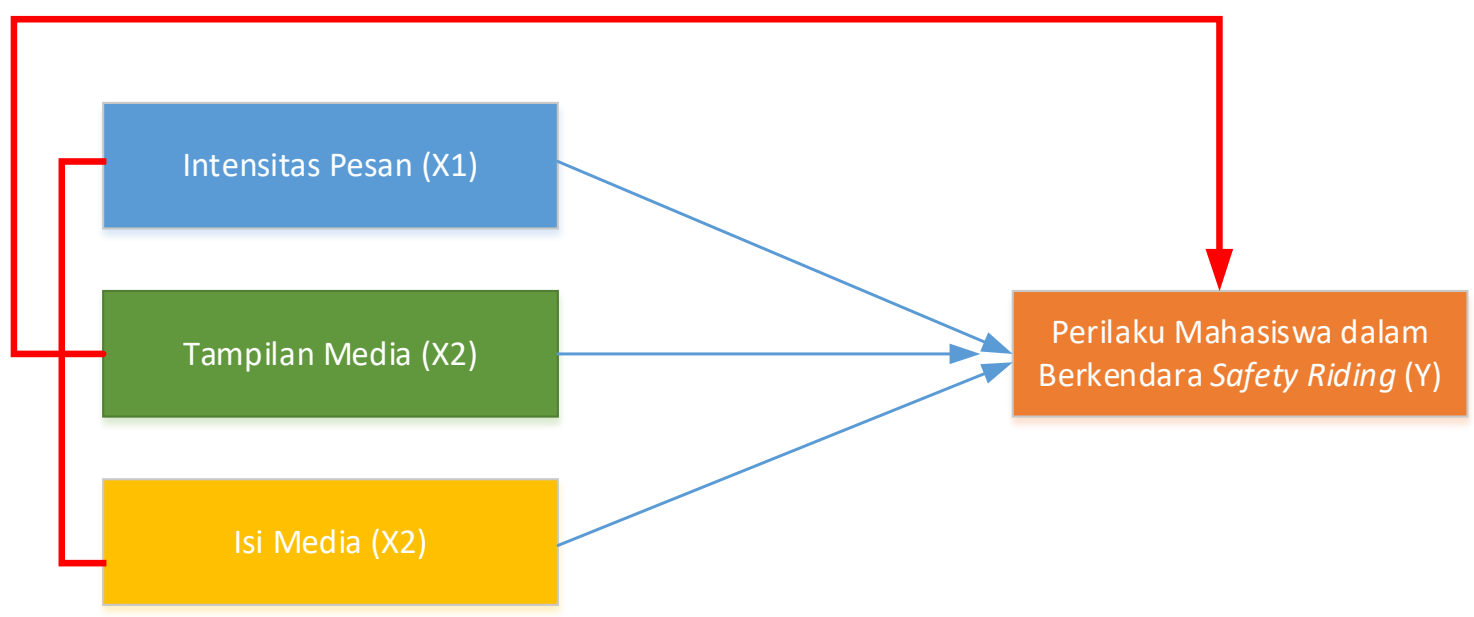

Gambar 1

Jalur Regresi Sederhana dan Ganda

(X1), Tampilan Media (X2) dan Isi Media

(X3) pada kampanye sosial safety riding dengan menggunakan media limbah kain batik terhadap perilaku mahasiswa UMC mengenai berkendara dengan aman. Peneliti menggunakan regresi sederhana dan regresi ganda untuk mengetahui pengaruh yang ditimbulkan. Regresi sederhana di gunakan untuk mengetahui pengaruh dari masing masing variabel. Sedangkan regresi berganda digunakan
2) Multikollinearitas

Multikollinearitas memiliki tujuan untuk menguji apakah model regresi ditemukan adanya korelasi yang tinggi antar variabel independen. Model regresi yang baik adalah tidak terjadi korelasi tinggi antara variabel independent. Untuk mendeteksi ada tidaknya gejala multikollinearitas dapat dilakukan dengan melihat pada nilai variance inflasi factor 


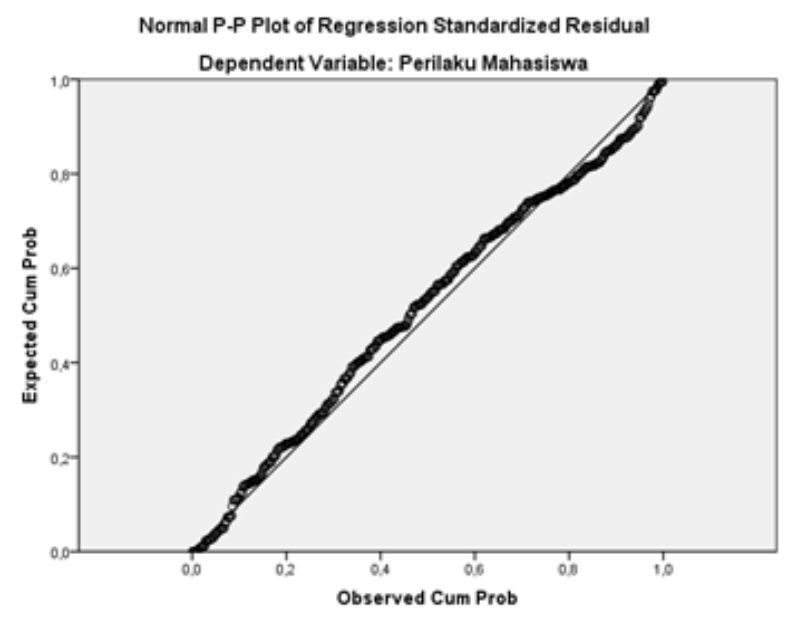

Gambar 2

Normalitas Data Penelitian

(VIF) dan tolerance pada output SPSS. Tidak terjadi kasus multikollinearitas bila VIF berada disekitar 1 dan nilai tolerance $=1 /$ VIF juga berada disekitar 1. (Sukestiyarno; 2011:81). Pada tabel 4 di bawah nilai VIF menunjukkan angka 1,004 untuk intensitas pesan, 1,098 untuk tampilan media dan 1,102 untuk isi media. Hal tersebut menunjukkan bahwa VIF berada disekitar 1 artinya tidak terjadi kasus multikollinieritas.

3) Autokorelasi

Uji autokorelasi bertujuan untuk mengetahui pemenuhan asumsi tersebut. Secara lebih kongkret untuk mengetahui apakah dalam model regresi linier ada korelasi tinggi antar eror satu dengan eror lainnya (tiap pengukuran observasi). Artinya kesalahan pengukuran slah satu observasi bergantung pada kesalahan observasi berikutnya atau sebelumnya. Untuk mendeteksi adanya gejala autokorelasi digunakan uji Durbin Watson (DW). Ketentuan jika $-2 \leq \mathrm{DW} \leq 2$ tidak ada autokorelasi. Artinya bila nilai DW di luar interval tersebut berarti terjadi kasus autokorelasi. (Sukestiyarno; 2011:82). Pada tabel 4 di bawah menunjukkan bahwa nilai Durbin Watson (DW) sebesar 1,833 artinya berada diantara $-2 \leq \mathrm{DW} \leq 2$ dan tidak ada autokorelasi.

4) Heteroskedastis

Uji heterokedastis digunakan untuk mengetahui pemenuhan asumsi bahwa varian memiliki kesamaan. Secara lebih kongkret dijelaskan bahwa heterokedastis muncul apabila eror atau residual dari model yang diamati tidak memiliki varian yang konstan dari satu observasi ke observasi lainnya. Untuk mendeteksi adanya kasus heterokedastis dilakukan dengan melihat diagram plot residual terhadap variabel dependen yang distandarisasi. Jika plot residual membentuk pola tertentu tidak bersifat acak terhadap nol makan dikatakan terjadi heterokedastis. (Sukestiyarno; 2011:82). 


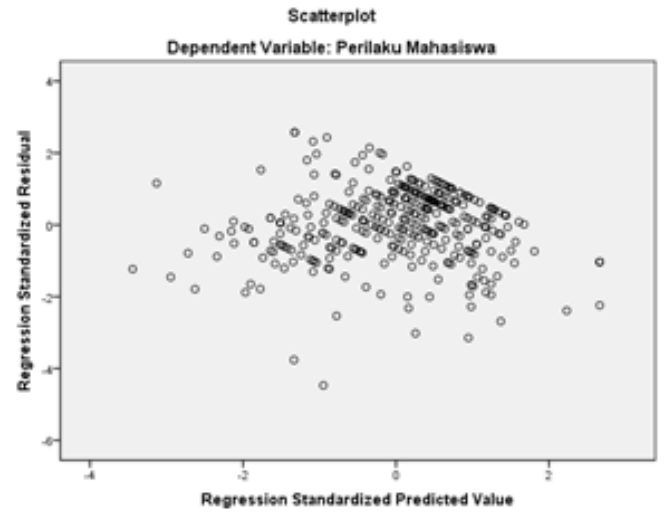

Gambar 3

Scatterplot

Pada gambar 3 di atas dapat dilihat pengecekan heteroskedastis antara galat (eror) yang terjadi (selisih prediksi variabel dependen dengan data observasi variabel dependen) dari sebaran plot di atas diketahui bahwa titik-titik yang terjadi menyebar disekitar garis nol, ada yang berada diatas garis nol ada pula yang berada di bawah garis nol dan tidak membentuk pola tertentu. Jadi asumsi bahwa varian error adalah identik terpenuhi. Artinya tidak adanya masalah heteroskedastis.

1) Regresi Linier Sederhana Pengaruh Intensitas Pesan (X1) terhadap Perilaku Mahasiswa (Y)

Uji regresi linier sederhana ini untuk mengetahui ada tidak nya pengaruh yang ditimbulkan Intensitas Pesan (X1) dari media kampanye sosial safety riding menggunakan media limbah kain batik terhadap perilaku mahasiswa UMC dalam berkendara aman $(Y)$.
Hipotesis :

Ho $: R=0$ : Tidak ada pengaruh Intensitas Pesan (X1) dari media kampanye sosial safety riding menggunakan media limbah kain batik terhadap perilaku mahasiswa UMC dalam berkendara aman (Y).

$\mathrm{H} 1: \mathrm{R} \neq 0$ : Ada pengaruh Intensitas Pesan (X1) dari media kampanye sosial safety riding menggunakan media limbah kain batik terhadap perilaku mahasiswa UMC dalam berkendara aman (Y).

Pengambilan keputusan:

Jika F hitung $\leq \mathrm{F}$ tabel atau probabilitas $\geq 0,05$ maka Ho diterima

Jika F hitung $>$ F tabel atau probabilitas $<$ 0,05 maka Ho ditolak 


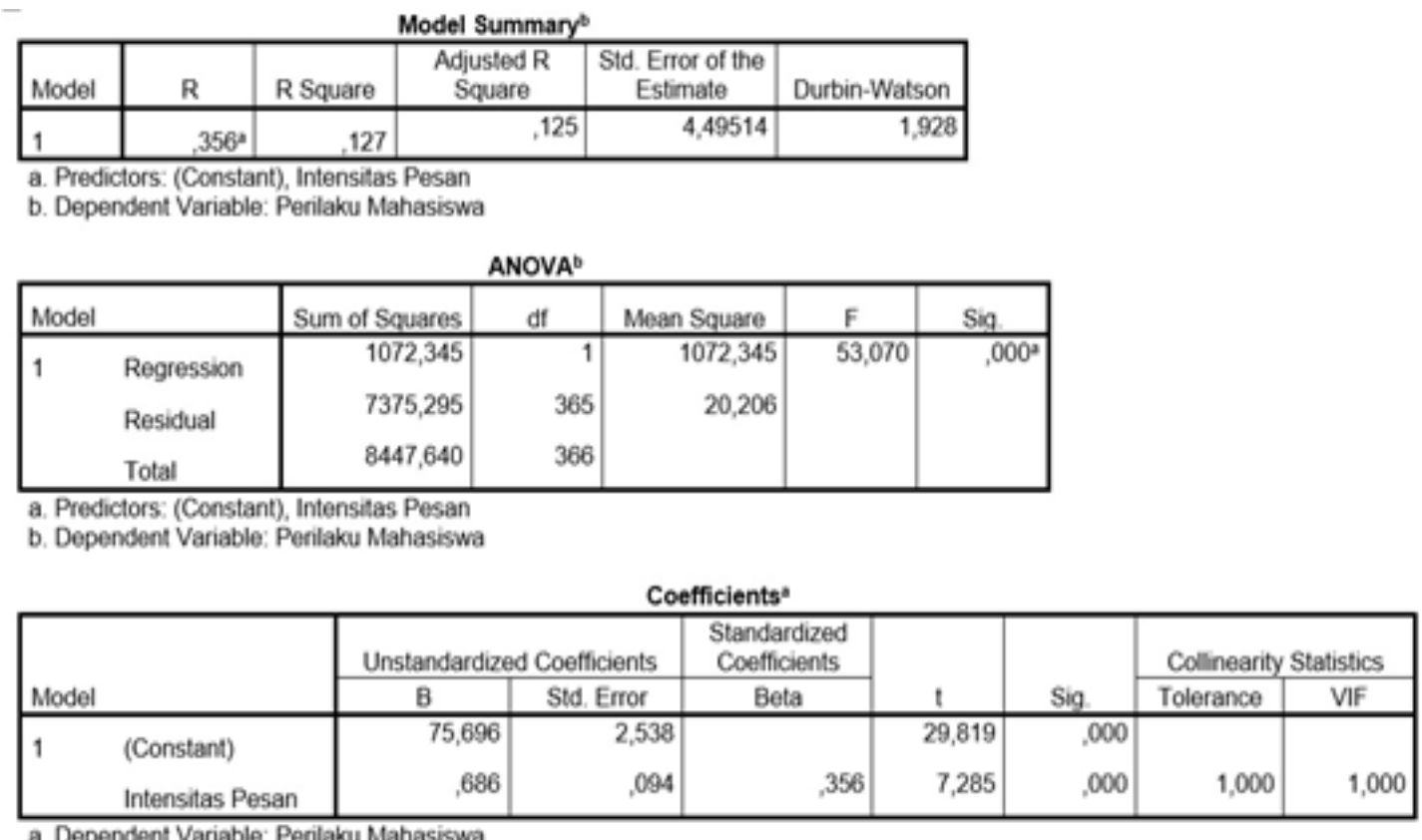

Tabel 1

Regresi Linier Sederhana Intensitas Pesan (X1) terhadap Perilaku Mahasiswa (Y)

Pada tabel 1 di atas nilai $F$ hitung menunjukkan angka 53,070 atau lebih besar dibandingkan dengan $\mathrm{F}$ tabel sebesar 3,68 (F hitung > F Tabel). Selain itu, nilai Sig atau probabilitas sebesar ,000 atau lebih kecil dari 0,05 (probabilitas $<0,05$ ) artinya H0 ditolak. Tidak ada pengaruh Intensitas Pesan (X1) dari media kampanye sosial safety riding menggunakan media limbah kain batik terhadap perilaku mahasiswa UMC dalam berkendara aman (Y) di tolak. Hal tersebut berarti "ada pengaruh Intensitas Pesan (X1) dari media kampanye sosial safety riding menggunakan media limbah kain batik terhadap perilaku mahasiswa UMC dalam berkendara aman $(\mathrm{Y})^{\prime \prime}$.

Nilai dari $\mathrm{R}$ sebesar 0,356 artinya hubungan antara Intensitas Pesan (X1) dari media kampanye sosial safety riding menggunakan media limbah kain batik dengan perilaku mahasiswa UMC dalam berkendara aman (Y) sebesar 35,6\% masuk katagori lemah. Sedangkan nilai R Square (R2) sebesar 0,127 artinya pengaruh Intensitas Pesan (X1) dari media kampanye sosial safety riding terhadap perilaku mahasiswa UMC dalam berkendara aman (Y) sebesar 12,7\%.

Pada tabel 1 di atas dapat dilihat bahwa koefisien arah regresi b1 sebesar 0,686 dengan konstanta (a) sebesar 75,696. Sehingga persamaan regresinya dapat diperoleh sebagai berikut :

$\mathrm{Y}=\mathrm{a}+\mathrm{b} 1 \mathrm{X} 1$

$\mathrm{Y}=75,696+0,686 \mathrm{X1}$

2) Regresi Linier Sederhana Pengaruh Tampilan Media (X2) terhadap Perilaku Mahasiswa (Y)

Uji regresi linier sederhana ini untuk mengetahui ada tidak nya pengaruh 


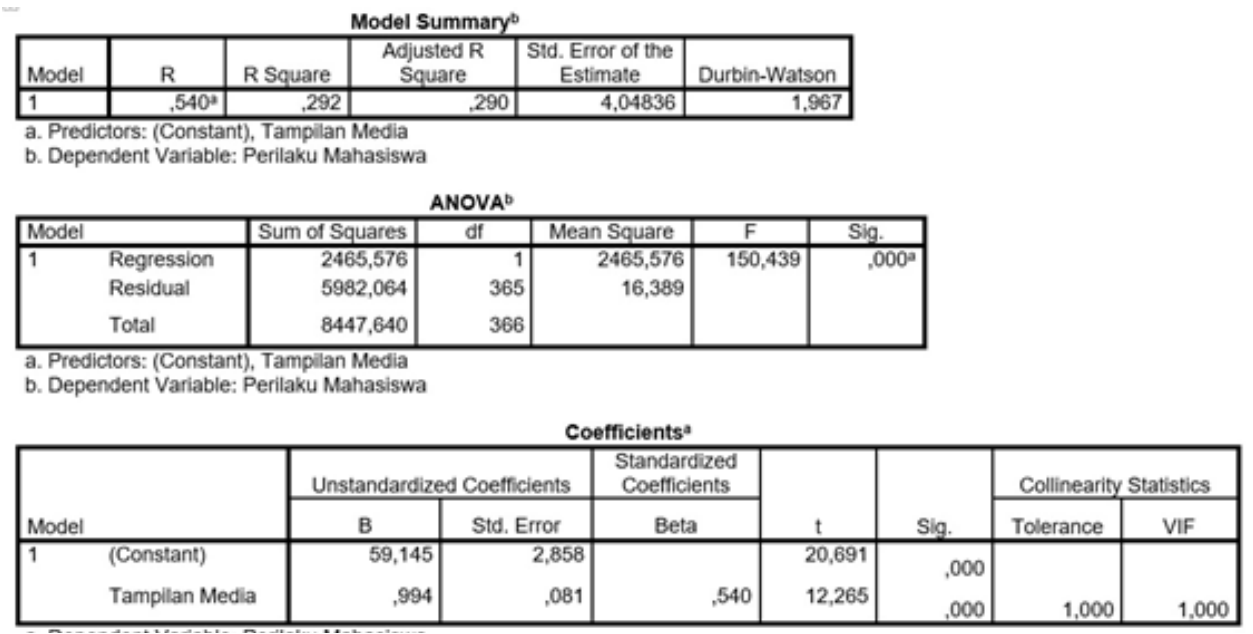

Tabel 2

Regresi Linier Sederhana Tampilan Media (X2) terhadap Perilaku Mahasiswa (Y)

yang ditimbulkan Tampilan Media (X2) dari media kampanye sosial safety riding menggunakan media limbah kain batik terhadap perilaku mahasiswa UMC dalam berkendara aman $(\mathrm{Y})$.

Hipotesis :

Ho $: R=0$ : Tidak ada pengaruh Tampilan Media (X2) dari media kampanye sosial safety riding menggunakan media limbah kain batik terhadap perilaku mahasiswa UMC dalam berkendara aman (Y).

$\mathrm{H} 1: \mathrm{R} \neq 0$ : Ada pengaruh Tampilan Media (X2) dari media kampanye sosial safety riding menggunakan media limbah kain batik terhadap perilaku mahasiswa UMC dalam berkendara aman (Y).
Pengambilan keputusan:

Jika F hitung $\leq \mathrm{F}$ tabel atau probabilitas $\geq 0,05$ maka Ho diterima

Jika F hitung > F tabel atau probabilitas $<$ 0,05 maka Ho ditolak

Pada tabel 2 di atas nilai $\mathrm{F}$ hitung menunjukkan angka 150,439 atau lebih besar dibandingkan dengan $\mathrm{F}$ tabel sebesar 3,68 (F hitung > F Tabel). Selain itu, nilai Sig atau probabilitas sebesar ,000 atau lebih kecil dari 0,05 (probabilitas < 0,05) artinya H0 ditolak. Tidak ada pengaruh Tampilan Media (X2) dari media kampanye sosial safety riding menggunakan media limbah kain batik terhadap perilaku mahasiswa UMC dalam berkendara aman (Y) di tolak. Hal tersebut berarti "ada pengaruh Tampilan Media (X2) dari media kampanye sosial safety riding menggunakan media limbah kain batik terhadap perilaku mahasiswa UMC dalam berkendara aman $(\mathrm{Y})^{\prime \prime}$.

Nilai dari $\mathrm{R}$ sebesar 0,540 artinya hubungan antara Tampilan Media (X2) 
dari media kampanye sosial safety riding menggunakan media limbah kain batik dengan perilaku mahasiswa UMC dalam berkendara aman (Y) sebesar 54\% masuk katagori sedang. Sedangkan nilai R Square (R2) sebesar 0,292 artinya pengaruh Tampilan Media (X2) dari media kampanye sosial safety riding terhadap perilaku mahasiswa UMC dalam berkendara aman (Y) sebesar 29,2\%.

Pada tabel 2 di atas dapat dilihat bahwa koefisien arah regresi b1 sebesar 0,994 dengan konstanta (a) sebesar 59,145. Sehingga persamaan regresinya dapat diperoleh sebagai berikut :

$$
\begin{aligned}
& Y=a+b 1 X 1 \\
& Y=59,145+0,994 X 1
\end{aligned}
$$

3) Regresi Linier Sederhana Pengaruh Isi Media (X3) terhadap Perilaku Mahasiswa (Y)

Uji regresi linier sederhana ini untuk mengetahui ada tidak nya pengaruh yang ditimbulkan Isi Media (X3) dari media kampanye sosial safety riding menggunakan media limbah kain batik terhadap perilaku mahasiswa UMC dalam berkendara aman $(\mathrm{Y})$.

\section{Hipotesis :}

Ho : $R=0$ : Tidak ada pengaruh Isi Media (X3) dari media kampanye sosial safety riding menggunakan media limbah kain batik terhadap perilaku mahasiswa UMC dalam berkendara aman (Y).

$\mathrm{H} 1: \mathrm{R} \neq 0 \quad$ : Ada pengaruh Isi Media (X3) dari media kampanye sosial safety riding menggunakan media limbah kain batik terhadap perilaku mahasiswa UMC dalam berkendara aman $(\mathrm{Y})$.

Pengambilan keputusan:

Jika F hitung $\leq \mathrm{F}$ tabel atau probabilitas $\geq 0,05$ maka Ho diterima

Jika F hitung > F tabel atau probabilitas $<$ 0,05 maka Ho ditolak
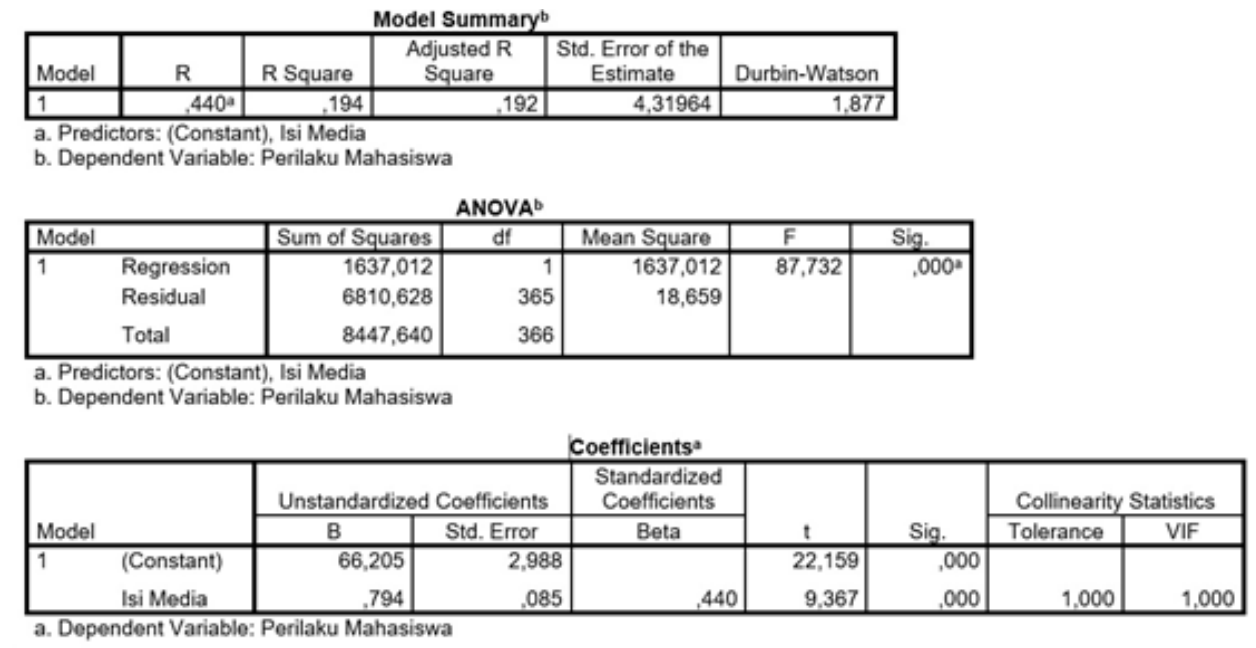

Tabel 3

Regresi Linier Sederhana Isi Media (X3) terhadap Perilaku Mahasiswa (Y) 
Pada tabel 3 di atas nilai $F$ hitung menunjukkan angka 87,732 atau lebih besar dibandingkan dengan $\mathrm{F}$ tabel sebesar 3,68 (F hitung > F Tabel). Selain itu, nilai Sig atau probabilitas sebesar,000 atau lebih kecil dari 0,05 (probabilitas < 0,05) artinya $\mathrm{H} 0$ ditolak. Tidak ada pengaruh Isi Media (X3) dari media kampanye sosial safety riding menggunakan media limbah kain batik terhadap perilaku mahasiswa UMC dalam berkendara aman (Y) di tolak. Hal tersebut berarti "ada pengaruh Isi Media (X2) dari media kampanye sosial safety riding menggunakan media limbah kain batik terhadap perilaku mahasiswa UMC dalam berkendara aman $(\mathrm{Y})^{\prime \prime}$.

Nilai dari $\mathrm{R}$ sebesar 0,440 artinya hubungan antara Isi Media (X2) dari media kampanye sosial safety riding menggunakan media limbah kain batik dengan perilaku mahasiswa UMC dalam berkendara aman (Y) sebesar 44\% masuk katagori lemah. Sedangkan nilai R Square (R2) sebesar 0,194 artinya pengaruh Isi Media (X3) dari media kampanye sosial safety riding terhadap perilaku mahasiswa UMC dalam berkendara aman (Y) sebesar 19,4\%.

Pada tabel 3 di atas dapat dilihat bahwa koefisien arah regresi b1 sebesar 0,794 dengan konstanta (a) sebesar 66,205. Sehingga persamaan regresinya dapat diperoleh sebagai berikut :

$\mathrm{Y}=\mathrm{a}+\mathrm{b} 1 \mathrm{X} 1$

$\mathrm{Y}=66,205+0,794 X 1$

4) Regresi Linier Ganda Pengaruh Intensitas Pesan (X1), Tampilan Media (X2), dan Isi Media (X3) terhadap Perilaku Mahasiswa (Y)

Uji regresi linier ganda ini untuk mengetahui ada tidak nya pengaruh yang ditimbulkan secara bersama-sama
Intensitas Pesan (X1), Tampilan Media (X2) dan Isi Media (X3) dari media kampanye sosial safety riding menggunakan media limbah kain batik terhadap perilaku mahasiswa UMC dalam berkendara aman (Y).

Hipotesis :

Ho $: R=0$ : Tidak ada pengaruh secara bersama-sama Intensitas Pesan (X1), Tampilan Media (X2) dan Isi Media (X3) secara bersamasama dari media kampanye sosial safety riding menggunakan media limbah kain batik terhadap perilaku mahasiswa UMC dalam berkendara aman $(\mathrm{Y})$.

$\mathrm{H} 1: \mathrm{R} \neq 0$ : Ada pengaruh secara bersama-sama Intensitas Pesan (X1), Tampilan Media (X2) dan Isi Media (X3) secara bersamasama dari media kampanye sosial safety riding menggunakan media limbah kain batik terhadap perilaku mahasiswa UMC dalam berkendara aman $(\mathrm{Y})$.

Pengambilan keputusan:

Jika F hitung $\leq \mathrm{F}$ tabel atau probabilitas $\geq 0,05$ maka Ho diterima

Jika F hitung $>$ F tabel atau probabilitas $<$ 0,05 maka Ho ditolak 


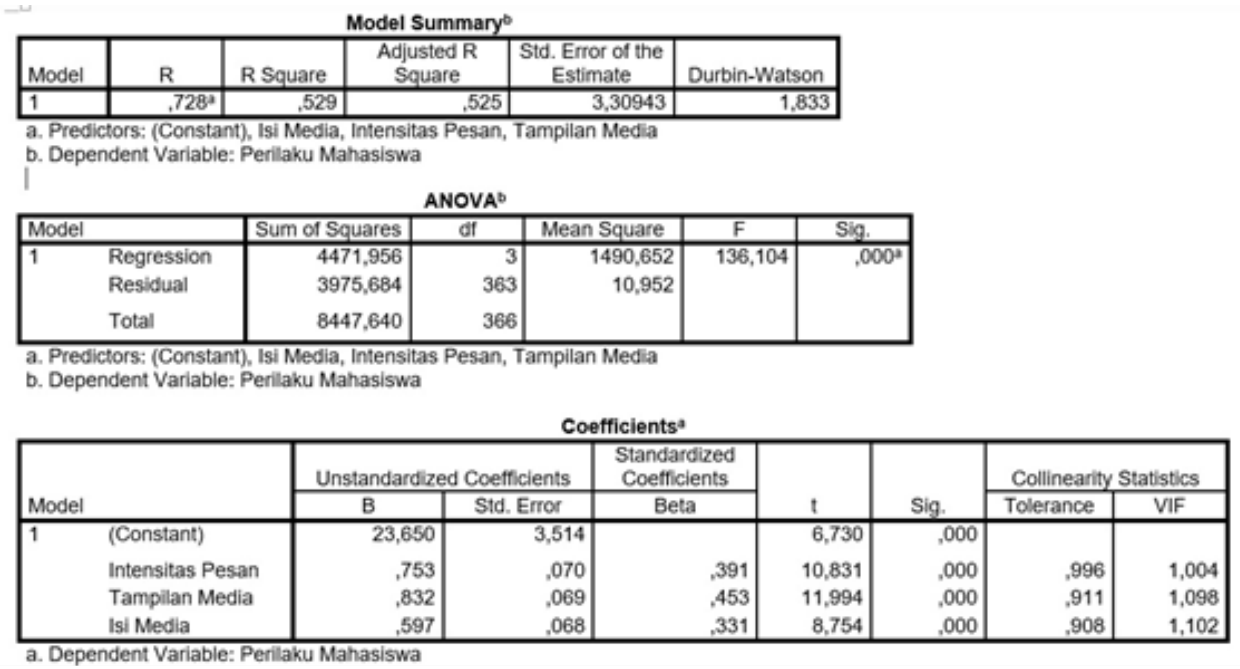

Tabel 4

Regresi Linier Ganda Intensitas Pesan (X1), Tampilan Media (X2) dan Isi Media (X3) terhadap Perilaku Mahasiswa (Y)

Pada tabel 4 di atas nilai $\mathrm{F}$ hitung menunjukkan angka 136,104 atau lebih besar dibandingkan dengan $\mathrm{F}$ tabel sebesar 3,68 (F hitung > F Tabel). Selain itu, nilai Sig atau probabilitas sebesar ,000 atau lebih kecil dari 0,05 (probabilitas < 0,05) artinya H0 ditolak. Tidak ada pengaruh Intensitas Pesan (X1), Tampilan Media (X2) dan Isi Media (X3) secara bersama-sama dari media kampanye sosial safety riding menggunakan media limbah kain batik terhadap perilaku mahasiswa UMC dalam berkendara aman (Y) di tolak. Hal tersebut berarti "ada pengaruh Intensitas Pesan (X1), Tampilan Media (X2) dan Isi Media (X3) secara bersama-sama dari media kampanye sosial safety riding menggunakan media limbah kain batik terhadap perilaku mahasiswa UMC dalam berkendara aman $(\mathrm{Y})^{\prime \prime}$.

Nilai dari $\mathrm{R}$ sebesar 0,728 artinya hubungan antara Intensitas Pesan (X1), Tampilan Media (X2) dan Isi Media (X3) secara bersama-sama dari media kampanye sosial safety riding menggunakan media limbah kain batik dengan perilaku mahasiswa UMC dalam berkendara aman (Y) sebesar 72,8\% masuk katagori erat. Sedangkan nilai R Square (R2) sebesar 0,529 artinya pengaruh Intensitas Pesan (X1), Tampilan Media (X2) dan Isi Media (X3) secara bersama-sama dari media kampanye sosial safety riding terhadap perilaku mahasiswa UMC dalam berkendara aman (Y) sebesar 52,9\%.

Pada tabel 4 di atas dapat dilihat bahwa koefisien arah regresi b1 sebesar 0,753, b2 sebesar 0,832, b3 sebesar 0,597 dengan konstanta (a) sebesar 23,650. Sehingga persamaan regresinya dapat diperoleh sebagai berikut :

$$
\begin{aligned}
& Y=a+b 1 X 1+b 2 X 2+b 3 X 3 \\
& Y=23,650+0,753 X 1+0,832 X 2+0,597 X 3
\end{aligned}
$$




\section{KESIMPULAN}

Dari penelitian yang telah dilakukan dapat diambil kesimpulan sebagai berikut :

1. Ada pengaruh Intensitas Pesan (X1) dari media kampanye sosial safety riding menggunakan media limbah kain batik terhadap perilaku mahasiswa UMC dalam berkendara aman (Y). Pengaruh Intensitas Pesan (X1) dari media kampanye sosial safety riding terhadap perilaku mahasiswa UMC dalam berkendara aman (Y) sebesar 12,7\%.

2. Ada pengaruh Tampilan Media (X2) dari media kampanye sosial safety riding menggunakan media limbah kain batik terhadap perilaku mahasiswa UMC dalam berkendara aman (Y). pengaruh Tampilan Media (X2) dari media kampanye sosial safety riding terhadap perilaku mahasiswa UMC dalam berkendara aman (Y) sebesar 29,2\%.

3. Ada pengaruh Isi Media (X2) dari media kampanye sosial safety riding menggunakan media limbah kain batik terhadap perilaku mahasiswa UMC dalam berkendara aman (Y). Pengaruh Isi Media (X3) dari media kampanye sosial safety riding terhadap perilaku mahasiswa UMC dalam berkendara aman (Y) sebesar 19,4\%.

4. Ada pengaruh Intensitas Pesan (X1), Tampilan Media (X2) dan Isi Media (X3) secara bersama-sama dari media kampanye sosial safety riding menggunakan media limbah kain batik terhadap perilaku mahasiswa UMC dalam berkendara aman (Y). Pengaruh Intensitas Pesan (X1), Tampilan Media (X2) dan Isi Media (X3) secara bersamasama dari media kampanye sosial safety riding terhadap perilaku mahasiswa
UMC dalam berkendara aman (Y) sebesar $52,9 \%$.

\section{DAFTAR PUSTAKA}

\section{Sumber Buku:}

Hutagalung, Inge.2015.Teori-TeoriKomunik asiDalamPengaruhPsikologi. Indeks. Jakarta.

Kriyantono, Rachmat. 2014. Teknik Praktis Riset Komunikasi. Kencana.Jakarta.

Lattimore, D, Otis B, Suzette, Elizabeth. 2010. Public Relations Profesi dan Praktik. Salemba Humanika. Jakarta.

Littlejohn, Stephen W dan Karen A. Foss. 2009. Teori Komunikasi. Edisi 9. Salemba Humanika. Jakarta.

Machfoedz, Mahmud. 2010. Komunikasi Pemasaran Modern. Cakra Ilmu. Yogyakarta.

Sukestiyarno.(2011).Olah Data Penelitian Berbantuan SPSS.Semarang: UNNES.

\section{Website:}

Korlantas Polri. 2017. Accident Data. http:/ / www.korlantas-irsms.info/graph/ accidentData. Diakses tanggal 04 Juni 2017.

Menristekdikti.2017.Pangkalan datahttp:/ / forlap.dikti.go.id/perguruantinggi/ detail/OTNFOC00NzcyLUIyNjU tQkUzNTEyQjAwQUQ0. Diakses tanggal 04 Juni 2017. 